\title{
CASES OF INJURY TO THE CERVICAL REGION OF THE SPINAL CORD.
}

\author{
BY WILLIAM THORBURN, M.D., B.S. (LOND.), F.R C.S.
}

Surgical Registrar to the Manchester Royal Infirmary, dec.

THE following cases of injury to the spinal cord have been treated in the Manchester Royal Infirmary since January, 1885 , and appear to be of sufficient interest to warrant their collective publication. For permission to make use of them I am indebted to the surgeons under whose care they have been admitted. I have also to thank the house-surgeons and dressers of the Hospital for much assistance in taking the notes, but I am especially indebted to the Resident Surgieal Officer, Mr. Joseph Collier, who has bad exceptional opportunities of observing most of these patients throughout their stay in the wards, and who has most generously placed his private notes at my disposal. Except where otherwise stated, the post-mortem examinations have been made by Dr. Harris, pathologist to the Infirmary. I may add that the cases are in no way selected, all injuries of the cervical region of the cord which we have admitted during the last eighteen months being hero included. We have, of course, had cases presenting slight bruises of the back, it may be with somewhat prolonged pain and weakness, but in none of these were there any symptoms of injury to the cord, and they are therefore not included in the present series. We have had no case of " concussion of the spine" in which spinal cord symptoms supervened on a remote injury, a general shake, or a slight local injury, nor have I ever seen such a case in the Manchester Infirmary.

The cases arrange themselves into two great classes, the one where the diagnosis was confirmed and the symptoms explained by the death of the patient and a post-mortem examination; 
the other where there was fortunately no such demonstration of the pathological condition. It will be convenient to consider first the cases in the former group, and then to endeavour, by the light thus gained, to realise more fully the significance of the remainder.

\section{Case I.-Fracture-dislocation between the Fifth and Sixth Cervical Vertebroe.-Complete Paralysis of all Nerves below the Fifth Cervical.-Death.}

L. F. wis ndmitted to the Manchester Royal Infirmary under the care of Mr. Jones on June 5th, 1886. The patient was a man, aged 68, a labourer by occupation. On June 1st, four days before admission, he was standing on a short ladder whitewashing, when, two of the rungs of the ladder giving way, he fell backwards in such a position that while his feet remained caught in the ladder, he first struck the back of his neck against a bench some two-anda-half feet above the ground, and his head then fell to the ground. $\Lambda t$ the same time he thinks that his bucket of whitewash fell upon him.

He at once became unconscious, remaining so for several hours. On regaining oonsciousness he found that his legs were quite immovable and his arms partially so, while there was numbness in the lower portion of his body, and insensitiveness to external impressions, coupled with a dull aching pain. There was also great pain in the head, neck, and shoulders. The urine lad to be drawn off twice duily. He remained in this condition until his admission to the Infirmary on the fourth day after the accident.

When admitted he was found to present complete paralysis of tho lower limbs, and of the abdominal and thoracic muscles. All the muscles of the arms were paralysed, with the exception of the biceps, brachialis anticus, supinator longus and deltoid, the consequence being that the elbows were flexed, the shoulder abducted and rotated outwards, and the hands and arms fell into the position indicated in the annexed engraving (Fig. 1, p. 512), taken from a photograph for which I am indebted to Mr. Sidebottom. There was no power of extension of the forearm, but a fair degree of puwer of flexion. Some rotation of the humerus could be effected, apparently by the fibres of the deltoid. The contractility of the supra- and infra-spinati was not ascertained; the pectoralis major and latissimus dorsi were paralysed. The lower limbs and truuk were completely anesthetic as high as 
the second rib in front,-i.e. as high as the descending branchus of the cervical plexus-and apparently to the third dorsal vertebra behind. Above this point sensation was normal. The upper extremities were anæsthetic, with the exception of the outer side of thefore arm and hand and the balls of the thumbs. Both cutaneous reflexes and tendon reactions were absent throughout. Breathing was entirely diaphragmatic. There was retention of urine, and the bowels had not been moved since the accident. The penis was subject to frequent erections with seminal emissions; on the back were several bed-sores. The pulse was slow and full; the

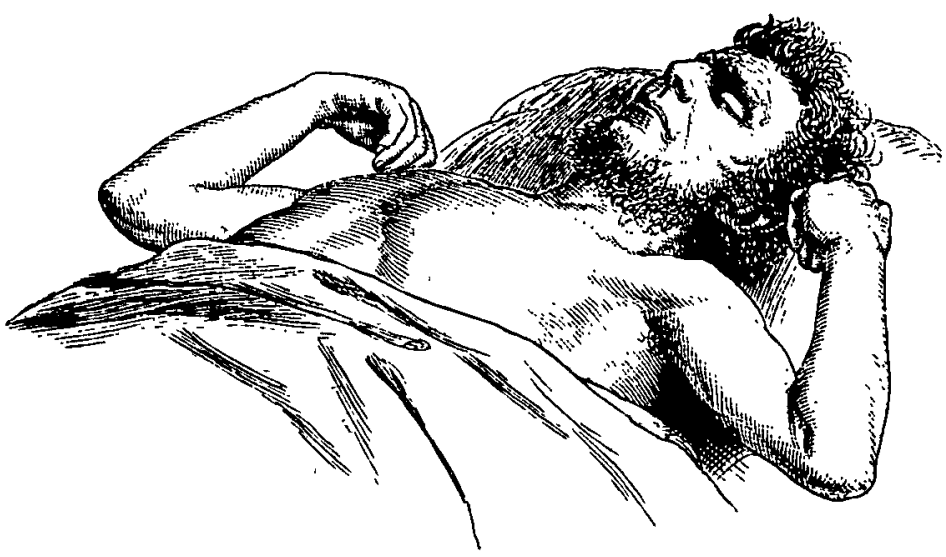

Fra. 1.-Position occupied by the limbs in a crse of complete transverse deytruction of the spinal cord immediately below the level of origin of the fifth cervical nerves.

temperature $98^{\circ}$. The pupils were both somewhat contracted. Over the 5th and 6th cervical vertebræ w'as a slight prominence, which was very tender on pressure. Tho only treatment adopted was complete rest on a water bed, catheterisation at intervals, and some simple dressing for the bed-sores.

During the progress of the case there were not many very important deviations from the symptoms above described. The urine, which was at first healthy, became turbid and alkaline a few days after admission. After this the bladder was washed out daily with boracic'lotion. Priapism became more constant. The bowels were never moved except after the use of an enema, or of crotosi oil. On June 9th, fonr days after admission, the arms had become, sompletely anæsthetic and remained so throughout. The temperature was generally slightly below the normal; the pulse 
was often 50, never above 60 . Respiration was rapid throughout, being usually about 20 , sumetimes 30 per minute.

'The patient's strength failed steadily, and at times there was confusion of thought, with low muttering delirium at night. He complained mainly of pain in the neck, and of cold feet.

On June 15th he had lost all power of rolating the humerus, on both sides, and passive movement of the shoulder-joints was very painful. The cheeks fell in and out very markedly on respiration. Although the power of the voice remained good, speech was almost unintelligible; he could not protrude tho tongue beyond the teeth, nor freely open the mouth. There was marked fibrillar trembling of the masseters; and much accumulation of tenacious saliva about the mouth. There were bed-sores over the sacrum, on the inner side of the right thigh, and on the inner side of the left knee, these having hardly changed since admission.

On June 17th the contraction of the deltoid muscles, which had maintained the abducted position of the arms, ceased, and the elbows fell to the sides, the elbow-joints themselves remaining flexed.

From this date the patient gradually sank, respiration becoming more laboured, and the countenance dusky, while there was increasing apathy. On June 25th the pupils were noted as being dilated and unequal, the right being the larger; there was a commencing "bed-sore" on the chest; on washing out the bladder there came away shreds of what was thought to be mucous membrane. On June 26th he died exhausted.

At the post-mortem examination was found depression of the 6th cervical spine and laminæ; the disc between the 5th and 6th vertebra was broken across, the upper part of the body of the 6th vertebra being tilted backwards. The lamina wero uninjured, but the right superior articular process of the 5th vertebra, and the corresponding transverse process of the 6th were broken off. At this point the cord was compressed, being flattened for a distance of about $\frac{1}{4}$ inch. The dura mater was here yellowish and opaque, the arachnoid and pia mater healthy. The cord was much softened for a distance of two or three inches ubove and one inch below the seat of injury, especially around the central canal, where it was quite diffluent and of a yellowish colour, showing under the microscope numerous granule cells. The rest of the cord was healthy. The bladder contained a quantity of blood-stained turbid fluid, its mucous membrane hanging in shreds, beneath which the wall was dark and livid; inflammation bad extended to the pelvic cellular tissue and vOL. IX. 
peritoneum. The kidneys were congested, and presented numerous. scattered points of suppuration; there was no dilatation of or suppuration in their pelves. The other organs presented nothing of interest.

This case is a sufficiently typical one of injury to the spinal cord above the origin of the 6th cervical nerves. The most interesting feature presented by it is the distribution of the paralysis and anæsthesia. Thus we find that, with the exception of the deltoid, biceps, brachialis anticus and supinators, there was absclute paralysis of the muscles of the upper extremity. The case is thus an exact counterpart of the socalled Erb's paralysis, in which we meet with paralysis of the above named muscles only, and enables us to confirm previous researches as to the distribution of the 5 th cervical nerve-root. Besides the intrinsic muscles of the arm there was certainly paralysis of the pectoralis major, which is supplied by the external and internal anterior thoracic nerves, and presumably also of the pectoralis minor. The latissimus dorsi appeared to be paralysed, and no doubt it had lost its nerve supply, from the long subscapular, as well as from the numerous smaller dorsal and lumbar branches, far below the seat of the lesion. That the subscapularis was paralysed appeared to be indicated by the external rotation of the humerus, in marked contrast to the internal rotation seen in Erb's paralysis and in obstetrical paralysis, where this muscle is spared. It was not found practicable to ascertain the condition of the teres major and minor, but the fact that the former is supplied by the middle subscapular would render it probable that it was paralysed with the subscapularis and latissinus, whereas the nerve to the teres minor is the circumflex, and we would therefore expect it to escape with the deltoid. The teres minor would also aid the posterior fibres of the deltoid in producing the well-marked external rotation of the humerus. The serratus magnus, supraand infra-spinati remain for consideration; but on the innervation of these three muscles we have here no information.

In Erb's paralysis these muscles escape, and would therefore not appear to be supplied by the 5 th root; in the closely-allied form of peripheral lesion described by Duchenne as " obstetrical paralysis," the spinati muscles are affected, and it would hence 
appear that the 4th cervical root supplies them with nerve fibres. Certain it is that they must be supplied by either the $4 \mathrm{th}, 5 \mathrm{th}$, or 6th cervical, inasmuch as their nerve, the suprascapular, is derived from the cord formel by these three, before its junction with any other root, and as the 6th root is found to supply the triceps, which is not affected in either Erb's paralysis, or obstetrical paralysis, we must refer the innervation of these muscles to the 4 th. Thus, then, we arrive at the result, that the 5th cervical nerve supplies only tho deltoid, biceps, brachialis anticus and supinator longus (with probably the supinator brevis and teres minor also).

As regards sensation, we find that a cord lesion which cuts off the whole of the nerves of the brachial plexus below the 5th cervical causes anæsthesia of the whole of the upper limb, except the outer side of the arm and forearm, and the radial border of the thumb, i.e., a part of the region supplied by branches of the musculo-spiral nerve. Possibly the area in which sensation was retained was at first more extensive than the above, inasmuch as the case was only seen for the first time four days after the injury, and we find that by the 8th day all sensation was lost in the upper extremity : a change due, no doubt, to extension of myelitis from the seat of injury. To this same zone of myelitis we must ascribe the contracted condition of the muscles supplied by the 5th cervical root, a contraction which slowly gave way to paralysis, as irritation was followed by destruction of the grey matter of the cord.

The affection of speech and other symptoms noted in the progress of the above case, at first gave rise to the supposition, that there might be some extension of myelitis to the medulla oblongata; but as no further symptoms of bulbar paralysis developed themselves, and as the intermediate cervical muscles were unaffected, these phenomena would appear to be due to the general debility only.

CASE II.-Fracture-dislocation between the Fourth and Fifth Cervical Vertebrae.-Complete Paralysis of Limbs and Trunk.-Death.

The following case was under the care of Mr. Heath. The notes were taken by the dresser, Mr. W. H. Iddon.

M. L., male, aged 45, was admitted on March 27 th, 1886. He 
had fallen from a scaffulding some forty feet in height. In addition to three lacerated scalp-wounds, he presented the following symptoms. There was severe pain in the back of the neck. All four extremities were completely paralysed, as were the muscles of the trunk and abdomen. The limbs and trunk were absolutely anæsthetic below a line running across the thorax at the level of the second intercostal space, and thence across the deltoids at tho junction of their upper and middle thirds ; above this line sensation was normal, the transition being quite abrupt. The pupils were equal, and appeared to be of normal size. There was no mental affection. Respiration was diaphraginatic; the urine was retained; priapism was constant. Death took place a few hours after admission, apparently from dyspnoea.

The temperature was taken several times, but was unfortunatoly not recorded. The house surgeon assures me that it was certainly not, at any time, far from the normal.

At the post-mortem examination there was found a fracture through the body of the 5th cervical vertebra, and the intervertobral disc immediately above it, The spines of the 3rd, 4th and 5th vertebræ were broken off. Outside the dura mater at this point was a very slight effusion of blood. The cord was much lacerated, being almost torn across opposite the seat of fracture, and was very soft for a distance of nearly $1 \frac{1}{2}$ in., being reddened by extravasated blood. The skull and its contents were uninjured. The lungs were cedematous.

The above case contrasts well with Case I. Here we have the lesion affecting the 5th vertebra and the disc immediately above it, so that the 5th root, which escapes from the spinal canal above the 5th cervical vertebra, would be injured, as well as all parts below. Hence we get complete paralysis of sensation and motion in the upper extremity, the whole of the brachial plexus being cut off from the brain, with the exception of the branch of the 4th cervical nerve. The present cases unfortunately yield no evidence as to the distribution of this branch, the condition of the posterior scapular muscles not having been specially noted.

CASE III.-Dislocation between the Fourth and Fifth Cervical Vertebro. -Complete Paralysis of Limbs and Trunk.-Death.

C. D. was admitted under the care of Mr. Hardie. The notes were taken by Mr. Benson, House-surgeon. The patient was a 
carter, 39 years of age. He was admitted on August 3rd, 1886, having fallen from a van, of which the wheels had passed over his shoulders.

On admission he complained of great pain at the back of the neck. All four limbs were completely paralysed, and there was anæathesia below the level of the descending branches of the cervical plexus. Respiration was diaphragmatic. The fæces were passed unconsciously. Both pupils were contracted, the palpebral fissures narrowed, and the eyeballs presented a remarkable sensation of softness owing to paralysis of the posterior orbital nuscles. Pulse was full, of low tension, and beating at the rate of 60 per minute. The temperature on admission, which was in the evening, was $96 \cdot 8^{\circ}$.

He passed a restless night, and on the next morning the following additional symptoms were noted. There was constant priapism. The urine was retained, and great difficulty was found in passing a catheter, due apparently to the extremedryuess of the urethra, as it entered readily after an injection of oil. The urine was examined for sugar and albumin, with negative results. The face was much congested; the pulse remained full and soft, beating at the rate of 130 per minute. The temperature at 8 A.M. was $102 \cdot 2^{\circ}$. An interesting fact noted by Mr. Collier was, that when the patient was told to take a deep breath, he produced contruction of the levator angnli scapulø muscle, which could be distinctly felt beneath the trapezius, thus indicating an attempt to fix the scapula, and bring into play the extraordinary muscles of inspiration.

At 10 A.M. the patient's temperature had risen to $103 \cdot 6^{\circ}$; at midday to $105^{\circ}$, at 2 P.M. to $106^{\circ}$. At 4 P.M. it was $107 \cdot 8^{\circ}$. He now became insensible and livid, and the breathing more shallow. The whole body was covered with a profuse hot sweat. At 5 P.M. he died, the temperature having risen to $108^{\circ}$. The temperature after death was not recorded.

At the post-mortem examination there was found a rupture of the cartilage between the bodies of the 4th and 5th cervical vertebre, these two bodies being so widely separated behind that a finger could be intruduced between them, They thus formed an obtuse angle posteriorly, pressing on the contents of the spinal canal. At this point there was marked post-mortem staining of the meninges, but decomposition was so far advanoed that it could not be ascertained whether they were inflamed. The cord itself was here compressed, through a vertical extent of $\frac{3}{4}$ of an inch, into a narrow band, and was very much softened, there being no distinction betweon the grey and the white matter. Elsewhere the cord shuwed only post-mortom softuning. 
The posterior parts of both lungs were much congested, and in the brain were numerous puncta oruenta. There were no other changes of interest.

This case is similar to the last, the lesion again involving the 5th cervical nerve and all parts below it, and the symptoms being the same. We shall refer again to such further points of interest as it presents.

CASE IV.-Fracture-dislocation between the Fourth and Fifth Cervical Vertebræe.-Partial Paralysis of Right Upper Limb.-Total Para. lysis of other Limbs and Trunk.=Death.

T. L. was adninitted under the care of Mr. Heath on Sept. 7th, 1886. He was 36 years of age, and a carter by occupation. While attending to his horse the animal had fallen against him, crushing him against a manger, the corner of which struck his back between the sboulders: He inmediately fell down paralysed.

On admission there was found no external brinise or other evidence of injury, except a sense of soreness and stiffness in the lower cervical spine; no irregularity of the spinous processes could be detected. The lower limbs and trunk muscles were entirely paralysed, as was the left upper extremity; the right upper extremity was paralysed with the exception of the deltrid and biceps (the condition of the braahialis anticus and supinator longus is not noted). The bladder and sphincter ani were also paral ysed, and there was priapism.

There was anæsthesia of the lower limbs and trunk, and of the upper limbs with the exception of the back of the hand, forearm and arm on both sides. Breathing was ontirely diaphragmatic. The pupils were widely dilated. The temperature was $100 \cdot 6^{\circ}$. The treatment consisted in the use of a water bed with ice-tubes to the spine, doses of ext. ergot. liq., three times daily, and catheterisation.

At 8 A.M. on the following day the temperature had risen to $105 \cdot 2^{\circ}$; at noon it was $104^{\circ}$; and then again gradually rose, reaching $105 \cdot 6^{\circ}$ before death, which occurred on the second day. Breatling became more difficult, with accumulation of mucus in the bronchial tubes, and the face grew very livid. He died asphyxiated about thirty-six hours after admission, the heart continuing to beat for some ten minutes after respiration had stopped. An unsuccassful attempt was made to save the patient by bleeding from the arn, artificial respiration, and stimulation with the furadic current. 
At the post-mortem examination there was found a rupture of the cartilage between the 4th and 5th cervical vertebræ, "which fracture had extended across posteriorly, involving the laminis of the 4th or 5th vertebre." The spinal mernbranes were healthy. The cord opposite the seat of fracture was not at all compressed, but was for a distance of about an inch very soft and pulpy, containing numerous punctiform hæmorrhages, which wero most marked in the central grey matter. The other organs were not examined.

This case presents an interesting comparison with Cáse I. on the one hand, and with Cases II. and III. on the other. The lesion of the spine itself was less severe, and there was less displacement of the bones, which consequently did not cause permanent compression of the cord. There was, however, ample evidence of a temporary crush of the spine, received, no 'doubt, at the time of injury, the bones afterwards recoiling partially to their normal position. Such, probably, is the explanation of many cases (as, for instance, our sixth case), where there is little or no evidence of bone lesion, but the cord itself has sustained a severe injury. An accident causes an acute bend of the vertebral column, which at once righis itself, but not before great or irreparable damage has been inflicted upon the contained organ ; and many of these cases have been regarded as instances of "concussion of the spinal cord," the possibility of a gross mechanical lesion being overlooked. Another point which is here exemplified, but which is more fully demonstrated in Case VI., is the tendency for hæmorrhage into the spinal cord to affect mainly its central portions, where its substance is softest and where the large branches of the central spinal artery have their distribution.

As regards the distribution of the paralysis and anæsthesia in this case, we find that there was not complete annihilation of the functions of the two 5 th cervical nerves. On the left side, the upper limb was completely paralysed, as in Cases II. and III., but on the right side the muscles supplied by the upper root of the brachial plexus had partially escaped, the biceps and deltoid not being paralysed. As regards the supinators and the brachialis anticus we have no information, and I did not see the case, but should suppose that these alsu 
probably escaped, although it is quite conceivable that their spinal motor cells may lie a little lower in the cord and may thus have been involved in the lesion. Further, we find that as in Case I., so here, sensation was retained in the distribution of branches of the musculo-spiral nerve, on the outer border of the arm, forearm, and hand of both sides.

CASE V.-Comminuted Fracture of Fifth and Sixth Cervical Vertebræ. -Partial Paralysis of Left Upper Limb._Total Paralysis of other Limbs and Trunk.-Death.

W. H. was admitted to Mr. Whitehead's wards on April 30th, 1886. He was 28 years of age, a wine-merchant by occupation, and of intemperate habita. When admitted be was intoxicated, and had, while in that condition, fallen over the bannistere of a staircase, the distance not being ascertained. He complained of great pain at the back of the neck; but there were no external signs of injury. There was complete paralyeis of both luwer extremities and of the right upper limb; but on the left side he could bend the elbow-joint. Respiration was diaphragmatic. 'The cutaneous reflexes and tendon reactions were abolished. Anesthesia was romplete below the branches of the cervical plexus, except over a portion of the left upper limb. The pupila were moderately contracted, the contraction-or rather imperfect dilatation-showing best, as is usual in these cases, in diffused light: the palpebral fissures were small. The pulse was slow and compressible. The temperature was not recorded, but was below the normal. The urine was retained, and the penis large and turgid.

A more complete examination showed, that while there was absolnte loss of motion and sensation in the right upper extremity, the paralysis had on the left side spared the deltoid, biceps, brachialis anticus and supinatur longus; the pectoralis major and latissimus dorsi, and all the muscles below the shoulder, with the exception of those mentioned, were paralysed. The arm occupied exactly the position assumed by those of Case I., being slightly abducted at the shoulder, rotated outwards, with the elbow flexed and the furearm and hand supine, the contrast between this position and the complete flaccidity of the right upper extremity being very striking. This was the first case in which this remarkable position of the limb was noted in the Manchester Infirmary, the detection of its significance being due to Mr. Collier. Its importance is shown by the fact, that it was found possible to ascertain the exact nature of the corl lesion before death. Anasthesia 
extended over the whole of the left upper extremity, except a strip of skin, some three inches wide, extending downwards from the shoulder, along the outer side of the limb to a point about three inches below the level of the elbow-joint.

The patient complained much of difficulty of breathing, which increased rapidly, and he died asphyxiated about forty hours after the accident. Before death the temperature becarne very high.

At the post-mortem examination, which was made by Dr. Bury, Medical Registrar, there was found a complete crush of the body of the 5 th cervical vertebra, the 4 th being displaced downwards and forwards, with its left transverse and articular process broken, and

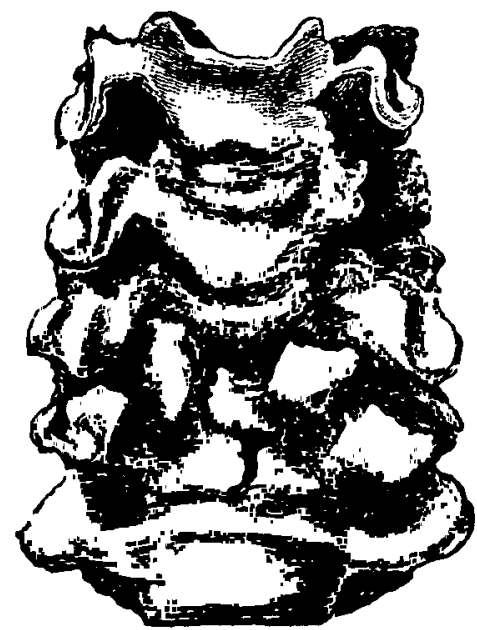

Fiu. 2.-Third, fourth, fifth, sixth and seventh cervical vertebre from Case V., scen from the front, showing a comminuted fracture of the bodies of the fifth and sixth vertebro.

the 6th split vertically : the condition of the bones is shown in Fig. 2. In front of the bodies of the injured vertebræ was some extıavasation of blood. On opening the spinal canal, the cord was found to be obliquely compressed in such a way that the upper limit of the flattening was above the 5 th cervical nerve on the right side, but between that and the 6th nerve in the left, as shown in Fig. 3 (p. 522), a small piece of the body of the fifth vertebra pressing upon the 5th root of the right side. The lungs were intensely congested, and portions of the left lower lube sank when thrown into water. The other organs presented nothing of interest.

This case, like the preceding one, is an instance of oblique 
injury to the cord, the direction of the obliquity being reversed, and the 5th root escaping on the left side only; and it thus offers another illustration of the distribution of the motor and sensory branches of this root. The area in which sensation was retained was Iess than in Cases I. and IV., owing probably to some of the lower fibres of the left 5th root also being involved in the lesion.

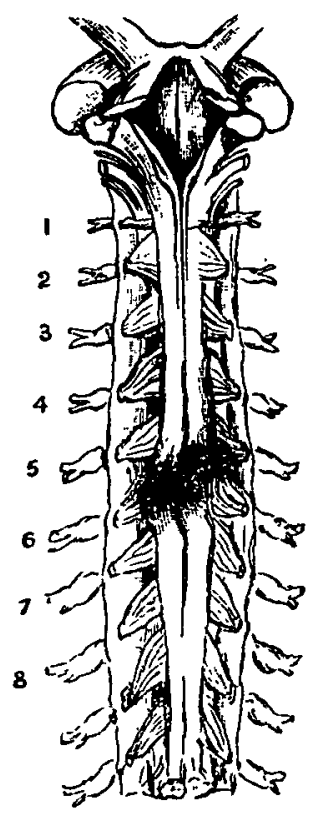

Fic. 3.-Spinal cord from Casc V., secn from behiud, showing compression, extending obliquely from above the origin of the sixth cervical nerve on the left side, upwards, so as to intercept the fifth nerve on the right side.

The above have been cases of fracture of the cervical spine, but the next on our list differs in that the lesion was not a fracture, but a traumatic hæmatomyelia, there being no obvious lesion of the spinal column itself.

\section{Gase VI.-Traumatic Hæmatomyelia in Lower Cervical and Upper Dorsal Region.-Death.}

J. B., aged 34 years, was adnitted on December 30th, -1885 , under the care of Mr. Heath, suffering from an injury to the spiue. He was a carter by occupation, aud was hurt, while loading a 
waggon, by a " tippler" full of coal falling upon him, so as to throw him upon his face, the coal striking him between the shoulders.

On admission to the Infirmary he was quite conscious, but stated that he had been rendered insensible for some time. by the injury. He had complete loss of power over both lower extremities, and complained of great pain at the back of the neck and between the shoulders, which was increased by moving the head. He had also pain from a severe bruise over the right elbow. On the left side of the head were three slight scalp-wounds.

A more careful examination showed him to have pain mainly over the 5 th and 6 th cervical vertebre, increased by pressure; but no irregularity was here detected in the spine. There was absolute paralysis of both lower extremities, with deficient action of the intercostal and anterior abdominal muscles in respiration, but good movement of the diaphragm. Both legs were completely anæsthetic as high as the knees; but thence upwards he had some sensation, although there was distinct numbness as high as a line drawn round the abdomen about two inches below the umbilicus. There was no hyperesthesia. The plantar reflexes were noted as "almnst absent," and the feet felt very cold, with some prickling sensation. He had distinct priapism. Both pupils were much contracted, but equal and contracting further on exposure to light. There was no vomiting and no mental affection. He was placed on a water bed, the scalp-wounds dressed, and ext. ergot. liq. administered in $38 s$ doses. In the evening the urine had to be drawn off.

On the following day there was still absolute paralysis of the lower limbs; but there was now no anæsthesia. The priapism had subsided, and the urine was passed without any trouble. The diaphragmatic respiration was very marked. On eximining the arms, which had not been done the day before, I found distinct feebleness of the flexors of the wrist and fingers on both sides; the grip was very feeble, but the power of extension against resistance little if at all diminished. Both superficial reflexes and tendon reactions were everywhere absent. The left pupil was somewhat contracted, but the right one very much more so; both contracted further on exposure to light. The patient had some vomiting during the night, and there were râles all over the chest. The morning temperature was $98.6^{\circ} \mathrm{F}$.; in the evening it was $99.8^{\circ} \mathrm{F}$.

On the following day, January 1st, 1886, his fæces were passed involuntarily. There was severe and painful cough, and all over the chost loud crackling râles; the countonance was cyanotic. 
No other change had occurred. Temp., morning, $99^{\circ}$; evening, $100^{\circ}$ The cyanosis and difficulty of breathing now rapidly increased, and there was dulness at the bases of both lungs, but no orepitations were heard. Without further symptoms, the man died on the night of January 2nd, 1886.

At the post-mortem examination there was found engorgement of the bases of both lungs and of the right side of the beart; but the other organs were healthy, with the exception of the spinal region, which is thus described. "A small dark black hæmorrhagic effusion existed in the muscles over the lower cervical and upper dursal regions." The membranes of the cord were quite normal, and the external appearance of the cord itself presented no evidence of injury; but "on section there was found to bo a dark black hæmorrhage into the central grey matter, in the lower cervical and upper dorsal regions. This hemorrbage, which measured in its vertical extent from $1 \frac{1}{2}$ to 2 ins., wis in the greater part of its extent situated centrally, occupying the wholo of the cential grey matter and extending but little into the white substance, which in its neighbourhood was merely softened and of a faintly yellow tinge. At the lower part, for a very short distance, the hromorrhage was limited to the anterior cornu of the right side, while the corresponding loft horn appeared to be porfectly healthy. Elsewhere the cord was firm, and presentod no abnormality."

The above case presents a large number of points of interest. In the first place, as regards the pathology, wo see here, as in Case IV., the tendency for hæmorrhages in the cord to affect the region immediately surrounding the central canal, where the vascular supply is very free. But the question which at once presents itself is, how are we to explain the occurrence of this hæmorrhage without an injury to the vertebral column? It appears to us impossible to suppose that it was due solely to concussion-to an indirectly-transmitted shake or jerk of the cord. If such were the method of its production, and if it were due to the cord being jerked forwards against the bodies of the vertebræ, we should expect the post-mortem evidence of the bruise, thus given to that delicate structure, to extend over a wider area: the cord would, in such an injury, be thrown forwards without any acute bend, and we should expect to find, not a single localised hæmorrhage, but a more diffused and extensive lesion. It appears far more probable that the mole 
of production of the injury was a sharp bend of the vertebral column at the region where it was struck-the blow being, as we have seen, a direct and severe one-the bones at once recoiling, but the more delicate cord being partially ruptured at the point of this sharp bend. A condition somewhat similar to this is seen in Case IV., where, however, the spinal column shows the effects of the strain to which it has been submitted, although it has recoiled sufficiently to obviate permanent compression of the cord. In the present instance we have only to suppose the injury to the framework to have been a little less severe than in Case IV., and the crush to its contained viscus to have been practically the same. This explanation of a temporary bend of the spine, with consequent injury to the cord, is advanced by Mr. Page in the July number of 'BraIN,' as the true pathology of MM. Duménil and Petit's case of "concussion" there described; and we would suggest that the present case not only confirms Mr. Page's view, but that the case which he quotes was probably of exactly the same nature as the one at present under consideration. Had our case survived for thirty-five days, as did that of MM. Duménil and Petit, we should have expected to find exactly the appearances described by them, viz. a patch of softening and discoloration at the point struck, with probably a secondary degeneration of the lateral columns below that region.

If, however, we are to assume the present case to be one of direct injury and not of "concussion" of the cord, it will be necessary for us to explain the various symptoms produced by this comparatively slight lesion, and this there appears to be no difficulty in doing. It is well recognised that in the case of cerebral hæmorrhage, we meet with two classes of symptoms, viz. those due to the actual destruction of a portion of the brain substance by the effused blood, which are permanent; and those due to compression of surrounding tracts or nuclei, which are more or less evanescent, their disappearance being conditional on the absorption of the blood and consequent diminution of the compressing force. Thus it may bo and often is the case, that the "compression symptoms" entirely overshadow the "destruction symptoms," and that a 
comparatively trifling hæmorrhage may cause extensive and more or less persistent compression of important portions of the brain. Precisely similar appears to have been the condition in the present case. The hæmorrhage itself occupied only the region of the central canal in the lower cervical and upper dorsal portions of the cord, extending to but a slight extent into the right anterior cornu. But this effusion of blood would suffice to cause more or less pressure upon the whole of the cord at this level, a pressure to which probably that structure would soon accommodate itself, having, as it has, ample room to expand. Perhaps then it will not be too bold an assumption to suppose that the direct symptoms, due to destruction of the grey matter by the blood, were insignificant; the other and more serious results of the injury arisiug from mere compression by this effusion.

There is no difficulty in attributing the paralysis of the lower part of the body to compression of the descending columns of the cord. The anæsthesia was partial only, becoming somewhat gradually less marked towards its upper limit, and this would coincide with the view, that the sensory fibres for the lower part of the body are more centrally situated in the spinal cord : a condition obviously convenient in view of the fact, that they have a longer course to travel. If this be their arrangement, we should expect exactly the condition which we find, viz. a more severe compression, and consequently more absolute loss of conduction of the deeper fibres, those most superficially situated having apparently escaped altogether. Again, in the case of the arm muscles, we find that the extensor muscles of the wrist and fingers have apparently escaped entirely, whereas the flexors are partially paralysed. Now, the hæmorrhage, extending as it did to the lower cervical region, would compress the anterior cornua in that region, and it is well recognised that it is from this portion of the cord that the flexors of the wrist receive their nerve supply: these muscles are not completely paralysed, as would be the case in a destroying lesion of their nuclei, but partially so, as we should expect in a compression lesion. On the other hand, the extensors of the wrist and fingers derive their nerve supply from a somewhat higher point in the 
cord, probably from the 6th or 7th cervical nerve, and these muscles are little, if at all, affected, while the muscles, already so often mentioned, which are supplied by the 5th cervical root, certainly escaped entirely. Finally, the early diminution of the anæsthesia, and of other symptoms such as the priapism and retention of urine, would well accord with the theory of their production by a compression of the conducting fibres, to which the latter rapidly accommodate themselves. On these grounds then we hold, that in no sense can the above case be regarded as one of concussion of the cord, but rather as one of a direct blow cuusing a small local hæmorrhage, with important symptoms.arising from the compression thereby induced.

We now leave the region of diagnosis by post-mortem examination, and pass on to the consideration of some cases of recovery after injury to the cervical spine.

Case VII.-Traumatic Hæmatomyelia in Middle Cervical Region. -Recovery with Persistent Symptoms.

W. H., aged 36, a carter, was admitted under the cure of $M r$. Hardie on June 13th, 1885. About half-an-hour before admission he had fallon between the shafts of a van which he was driving, one wheel of which had passed orer his shoulders. It may bo remarked that there was no history of syphilis.

On admission he lay quite helpless, there being complete paralysis of the left arm and of both legs, while the right arm was partially paralysed, but retained some motor power "especially at the elbow." Respiration was diaphragmatic. The reflexes were normal. There was anæesthesia below the distribution of the cervical nerves. Speech was laboured, owing to difficulty in breathing, but there was no loss of consciousness or mental confusion. The left pupil and palpebral fissure were slightly smaller than those of the right side. There was much pain in the back of the neck, but no abnormality was there detected. After he had been put to bed, he was able to move the right lower extremity slightly. He was placed on a water bed, the head being fixed by sand-bags. There was great thirst and dryness of the mouth. '

The urine had to be drawn off; it was acid, of a specific gravity of 1010 , and contained neither sugar nor albumin. He passed a fairly good night.

On the following morning it was ascertained that sensation was nowhere absolutely lost, but that it was inpaired on both sides of 
the body, but more markedly on the right than on the left. There was more power of moving the right leg and arm; the limbs of the left side remained completely paralysed. Other symptoms continued as before; the temperature was, in the morning, $100^{\circ} 2$ in the evening, $101^{\circ}$. There was free perspiration, the urine was scanty and high-coloured.

When examined on June 15th, forty-eight hours after the accident, he was feeling much better and had less pain in the neck. He had more power over the right arm and leg, and an examination of the arm showed that the rhomboids, posterior scapular muscles, deltoid, biceps and supinator longus acted well, whereas the other muscles of this limb were paralysed. The left arm and leg remained completely paralysed. Sensation was returning on both sides, but remained less acute on the right than on the left side. This diminution of sensation extended as high as the supraclavicular branches of the corvical plexus. The reflexes were normal. There appeared to be some slight movement of the intercostal muscles in respiration. The pulse was beating at the rate of 102 ; the temperature was, in the morning $102^{\circ}$; in the evening, $102^{\circ} \cdot 4$.

- On the following day there was further gain of sensation and of power on the right side. On the left side were slight pricking sensations. The temperature had fallen to $99^{\circ} \cdot 4$. Other symptoms were as before. It was noted that there had throughout been no priapism.

On June 17th he passed his urine without the use of a catheter, and had no further trouble with it. Bis bowels were now oponed for the first time since the accident. The pulse remained somewhat rapid, being 85 in the morning and 100 in the evening; the temperature was $101^{\circ}$. On the 19 th there was distinct costal respiratory movement. The pulse was still rapid and the temperature $100^{\circ}$. On the 26th the temperature for the first time reached the normal, at which it afterwards remained, except temporarily on two unexplained occasions.

On June 24th there seemed to be little or no further change. He was ordered iodide of potassium in gr. 10 doses. From this point improvement progressed very slowly. On July 4th he was able to move his shoulders slightly on both sides, and the intercostal muscles acted more freely on the right than on the left side; there was no other change in the paralysis. The knee-jerk was exaggerated on both sides; there was no ankle-clonus. On July 20th he was transferred to the medical wards under the care of Dr. Ross, where very full notes of his condition were taken by Dr. Bury, Medical Registrar, of which an abstract only is here 
givon. At this time it was noted that costal respirition was still deficient, being apparently more so in the lower ribs (probably because the downward traction of the diaphragm was able to overcome the expansion).

The following was the condition of the right upper limb:-The wrist was semiflexed and somewhat inclined towards the ulnar side, having very slight power of flexion and extension. The thumb lay fully extended, but could be slightly flexed, adducted and abducted : there being, however, no power of opposition. The first phalanges of the fingers were extended, the second and third partially flexed; there was slight power of flexion of the metacarpo-phalangeal joints, but no movement at the inter-phalangeal joints. As regards latera? movement there was slight power of abduction and adduction of the first and fourth fingers, but the second and third were immovable, having always a slight interval between them. He could pronate the wrist and then bring it half-way into the supine position, but not beyond this. The elbow was semiflexed and could be partially flexed, but $n$ ot extended and passive extension caused the tendon of the biceps to stand out very sharply. At the shoulder-joint there was diminished movement, especially of abduction, external rotation and flexion; he could touch the tip of the opposite shoulder but not his head. There was marked wasting of the whole limb. A very powerful faradic current caused slight contraction of the extensors and flexors of the elbow, and of the erratus magnus, but of none of the other muscles of the limb or shoulder. The galvanic current gave the "reaction of degeneration" with the pectoralis major, deltoid, supra- and infra-spinatus, biceps, triceps, extensore and flexors of the forearm and muscles of the hypothenar and thenar eminences. On the left side the condition was similar, except that there was even less power of voluntary movement. In brief, there was well-marked "atrophic paralysis" of all muscles supplied by the brachial plexus. 'I'be movements of the lower liwbs were weak, but of normal range, except for some deficiency at the left ankle, and the electric reactions were also here normal.

It was not easy to map out fully the extent of sensory deficiency, owing to the fact that there was nowhere ab:olute anæesthesia, nor any defined limit. On both sides sensation was normal in the neck, and as far downwards as the lower limit supplied by the cervical plexus, that is, to the level of the third rib. There was below this limit marked diminution of sensation on the right side extending to witbin $\frac{1}{2}$ inch of the middle line in front: at this point there was an area of transition, and to the left of the middle line sensution was normal. Behind, the anesthetic area extended over the whole of the right side of the trunk as far as a voL. IX. 
vertical line, midway between the posterior border of the right scapula, and the spines of the vertebræ; the upper limit of anæesthesia being here the spine of the scapula. The right shoulder was not anæsthetic. There was no anæsthesia of the left half of the trunk. The right lower limb was anæsthetic, the left was not-in fact, there was partial anæsthesia of the whole of the right side of the trunk and lower extremity, with normal sensation on the left side. In the upper limbs the distribution of anæsthesia was symmetrical, affecting the whole of the limbs, excepting a strip of skin, running from the shoulder, along the centre of the biceps, and then straight downwards along the front of the forearm to the hind, where it spread out, so that the only part of the hand which was anæsthetio was the thumb, the rest having apparently normal sensation both in front and behind.

The knee-jerk was much exaggerated, and there was marked ankle-clonus; the superficial reflexes were absent, and there were no reflexes in the upper limbs.

The skin over the anæsthetic areas was hot and dry, the slightest prick or scratch causing a bright red spot or line. Thero was slight swelling and tenderness at the back of each wrist. The inter-phalangeal joints were also thought to be slightly swollen, but were probably merely rendered more prominent by the general atrophy. The finger-nails were long, the skin at their roots being red, smooth, and shining.

The left pupil was slightly smaller than the right, and the left palpebral fissure somewhat narrowed.

The patient remained under observation for rather more than three months after this, taking a mixture of iron and quassia. During this time voluntary power increased considerably in the right upper extremity, and to a slight extent in the left; when last seen he could move the fingers of the right hand fairly well in all directions, had slight power of opposition of the thumb, cuuld raise the elbow to the level of the shoulder, and could touch the top of the head with his hand. Sensation had also improved. There was still some difficulty in moving the left ankle, but otherwise the movements of the lower limbs were good.

Superficial reflexes were obtained over the abdomen; the cremasteric reflexes were still absent, the plantar was got on the right side only. The knee-jerk was less marked on the right side than it had been, but was unaltered on the left. There was no other change, and the vital functions were well performed.

Regarded in the light of the preceding cases, there can be little difficulty in following the course of events in the present 
instance. The primary lesion was probably a hæmorrhage into the cord situated similarly to. that of Case VI., but of somewhat greater extent. On the left side it appears to have extended sufficiently high to annihilate, either by pressure on or by destruction of the grey matter, the whole of the functions of the nuclei connected with the brachial plexus of that side. On the right side the nuclei of the 5th cervical nerve have escaped, as have the pupillary fibres. The parts of the cord below this point have also been affected, probably owing to compression of the conducting tracts, and thus we find partial anæsthesia, which undergoes gradual improvement; and retention of urine, which soon passes off. It is noticeable that this is the only one of our cases of cervical injury in which there was no priapism, and that in Cuse VI., which was also an instance of mere temporary compression of the conducting paths, priapism was of short duration. In the present instance, as in Case VI., there is paralysis of the lower part of the body, owing to pressure on the lateral columns, and at a later stage we have clearly developed the symptoms of descending degeneration of those columns. The simplicity of the case is, however, interfered with apparently by a localised myelitis arising round the hæmorrhage and thus causing some extension of its destructive effects. Hence in the later stages of the case we find the 5th cervical nerve losing its functions on the right as well as on the left side. That the left side was the more severely injured is evidenced by the fact, that the anæsthesia was more complete and more permanent on the right side of the body. It will also not escape notice that, whereas the muscles supplied by the brachial plexus presented the "reaction of degeneration," those of the rest of the body did not, thus evidencing farther a "destroying lesion" of the grey matter of the cord in the lower cervical region on the one hand, and a mere interference with conduction to the parts below on the other. In the same way we find that in the case of the brachial plexus, sensation is impaired on both sides, whereas, below this point, the anæsthesia is limited to the right half of the body, corresponding with the obviously greater extent of the lesion on the left side of the cord. 
The most difficult point in this case is to explain the localisation of the anæsthesia in the upper extremities. This loss of sensation affects both limbs symmetrically, involving two areas, viz. the outer side of the limb, supplied by the 5th cervical root, and the inner side, supplied by the 8th cervical and 1st dorsal, but omitting the intermediate portions which derive their sensory nerve supply from the 6th and 7th cervical roots. The explanation of this remarkable localisation, given by $D_{r}$. Ross, under whose care the patient was placed, and for whose inspiration upon both this and other subjects I cannot sufficiently express my indebtedness, is as follows: That the hæmorrhage did not extend far, if at all, below the level of the 5th root, the atrophic paralysis below this point being due rather to subsequent myelitis, which would produce less serious mischief, and would affect mainly the grey matter of the anterior horns. That thus we have, at or about the level of the 5th cervical root, a destroying lesion affecting nearly all the structures of the cord, but that below this point the conducting fibres largely escape. That the sensory fibres of the 5th nerve are injured immediately on their entry into the cord. That the fibres of the 6 th and 7 th roots, crossing obliquely as they do, and probably very superficially, are, at the level of the 5th roots, so near the periphery as to escape injury; but that the fibres of the 8th cervical and 1st dorsal nerves have probably already completely crossed over before reaching the level of the 5th root, and having thus acquired a deeper site have again come within the influence of the lesion. The great difficulty which this ingenious theory presents is that, on the left side of the body, there is no anæsthesia below the level of the 1st dorsal nerveroot, and that thus we have not sufficient evidence of compression or other injury of the sensory conducting paths on the right side of the cord. Possibly the explanation may be that the hæmorrhage or subsequent myelitis had taken a somewhat irregular direction, extending into the nuclei of some of the roots but not of others ; or that, as in Case IV., there were two or more scattered hæmorrhagic foci.

We have only to note further, that here, as in Case VI., the cause of the intra-medullary hæmorrhage was apparently 
nn acute bend of the cord, due to the direct, application of great violence.

CASE VIII.-Traumatic Cervical Hæmatomyelia.-Temporary Paralysis of Limbs and Trunk.-Recovery.

W. B., aged 40, was admitted to Mr. Heath's wards on Aug. 15th, 1885 , suffering from the results of a fall estimated at a distance of 50 feet. He was a strong, healthy-looking man with no trace of previuus illness. On the right side of the head was a deep scalpwound, extending about 4 inches backwards from the forehead, and surrounded by much bruising. It may at once be said that under ordinary treatment this wound soon healed up. There was no unconsciousness, nor other trace of cerebral symptoms. All four limbs were, however, paralysed ; the arms completely so; the legs could be moved in bed, but the patient could not stand. He had complete anæsthesia of the arms, abdomen and legs, but no loss of control over the rectum and bladder. The skin over the lumbar spine showed extensive bruising. Unfortunately, the notes of this case were very imperfectly taken, and there is no further information contained in them.

On the following day the temperature rose to $99 \cdot 2^{\circ} \mathrm{F}$., in the morning, and $100 \cdot 8^{\circ} \mathrm{F}$., in the evening: there was more power in the lower limbs and muscles of the neck. On Aug. 17th, he could move his legs quite easily and freely in bed, and there was no sign of paralysis of the neck, but both arms remained completely paralysed. Sensibility was improved, but there were tingling sensations in all the limbs. The temperature was lower. On the 18 th sensibility appeared to have quite returned. The fingers and thumb could be moved fairly well on both sides, and there was slight movemont of the whole upper limb. The temperature bad returned to the normal, at wbich it afterwards remained. From this time there was a slow but steady gain in power, and on Ang. 28th, the upper extremities could be moved in any direction, but only feebly so. It was, however, snme time before the legs were sufficiently strong to support him. He was first able to walk a little on Oct. 12th, and could then use his arms for such light work as holding a book, but they were still weak; there was no marked muscular wasting-merely the emaciation due to lying in bed; there was marked ankle-clonus, and exaggerated patellar, triceps and radial reflexes. The only affection of sensibility was some numbness of the inner sides of the calves, with tingling sensation in the fingers.

Three days later he was sent to the Convalescont Hospital at 
Cheadle, where the constant current was applied to various parts of the limbs three times weekly, and where strength rapidly returned.

I again saw the patient on Jan. 16th, 1886, i.e. five months after his accident. He then looked very well and had returned to his work, but still felt weakly and had the sensation of tingling in the fingers; there was, however, no anæsthesia, and no difficulty in using the hand. He stated that at times he had some girdling sensation, which he referred to the region of the lower dorsal and upper lumbar nerves. The patellar and radial "deep reflexes" were exaggerated, but there was no ankle-clonus and no jerk on striking the triceps tendon.

The symptoms of this case are entirely explicable on the supposition, that the patient had a hæmorrhage into the cord, affecting the central grey matter at the level of the brachial plexus. This appears to have been small, and to have renclered itself obvious only by causing compression. There was no priapism, and no affection of the bladder or rectum, so that conduction to and from the lumbar centres was even less interfered with than in the two preceding cases. Anæsthesia also was very temporary, thus showing once more how rapidly the sensory fibres of the cord may accommodate themselves to slight pressure. It is interesting to note that as the anæsthesia passed off there was developed some "tingling " sensation, which we saw also in the last case under analogous circumstances. Here also, as in Case VII., we have some descending degeneration of the pyramidal tracts, due probably to pressure, and evidenced by the spastic symptoms in the lower limbs. That the effusion of blood was small, and did not extend to the anterior cornua, is indicated by the fact that there was no atrophy in the muscles of the upper limb. Unfortunately, the circumstances of the accident do not, in this case, allow of our exactly determining the nature of the injury to the spine, but it seems at least probable, from the presence of the severe scalp-wound, that the man fell upon his head, and that then there was an acute bend of the spine in its most vulnerable site, the whole weight of the body acting as a lever to bend the spinal column at this point. The bruise over the lumbar spine was clearly due to a less severe blow than that which cansed the scalp-iwound, and probably resulted from the body 
striking the ground after the head. This is precisely the explanation given by Mr. Page of MM. Duménil and Petit's case of "concussion" already quoted; and, indeed, the last three of our cases appear to me to confirm most strongly the views set forth by Mr. Page in the article above referred to.

\section{CASE IX.-Traumatic Meningeal Hæmorrhage (?)._-Paralysis of Limbs and Trunk.-Partial Recovery.}

M. H., a widow, aged 37, was admitted under the care of Mr. Jones, on May 10,1886. Five weeks previously, she received two bullet-wounds from a revolver, probably fired at a distance of about two yards. One bullet pierced the left thumb and then passed through the lobe of the left ear, grazing the mastoid procesn and apparently at once escaping. The other entered immediately below and behind the left mastoid process, passing downwards and to the right. She was "immediately" paralysed in all four limbs, and when seen by a medical man was found to have complete loss of sensation below the neck, diaphragmatio breathing, and incontinence of urine and fæces. An attempt was made to find the bullet, but proved unsuccessful. The wounds healed well in abont a fortnight, during which time the nervous symptoms were said to have remained unchanged. Calomel was occasionally administered to regulate her bowels, and her limbs were rubberl with oil.

On admission to the Infirmary five weeks after the injury, she was found to be a well-nourished and healthy-looking woman. In addition to the scals left by the above-mentioned wounds, she presented the following symptoms. At the back of the neck, some 3 inches to the right of the 5 th cervical spinous process, was felt a hard nodule, apparently the bullet, lying quite superficially. She felt pain on moving the head, and tenderness of the cervical spine. There were no cerebral symptoms. The upper limbs were completely paralysed. The lower extremities were less absolutely so : on the left side she had some power of extension and flexion of the ankle-joint, and could raise the limb slightly from the bed; on the right side there was even less moverwont of the foot. The abdominal and intercostal muscles were also paralysed, breathing being diaphragmatic. There was no anesthesia, but slight hyperasthesia about the shoulders. The superficial and deep reflexes were normal. The limbs did not appear wasted. There was incontinence of urine and feces. The temperature was normal, and remained so throughont the patient's stay in hospital. There wero no circulatory or digestivo disturbances. 
A few days later, Mr. Jones removed the bullet without difficulty from the site above indicated. It proved to be a conical revolveroullet, abont $\frac{3}{4}$ in. long and flattened at the apex from contact with sume hard substance. The wound healed readily, and gave no trouble.

On May 19th were noted involuntary twitchings of the legs, which were very constantly present and continued during her stay in hospital. On the 25th, she was found to have some slight power of movement of the fingers of her left hand, and increasing power in the movements of the feet. The faradic ourrent was regularly applied to the limb muscles, the electric reactions of which were normal. Shortly after this she commenced to move the abdominal muscles, and to a slight extent the intercostals: the power of all of these slowly increasing. Towards the middle of June she became able to move slightly the fingers of the right hand, but there was little improvement elsewhere. She complained a good deal of occasional wandering sensations, of " pins and needles," and of the almost constant muscular tremors. From this time, until she went home on July 30th, there was no change, except a slight increase in the power of the already-acquired movements.

By kind permissiın of Dr. Martin, her medical adviser, I saw this patient again, at her own home, in September. As regards motor power, there was little or no change from the time of her leaving the Infirmary. The limbs were not more wasted than would be expected from her long confinement to bed, and the muscles every whero presented normul electrio reactions. The knee-jerk was much exaggerated, and there was ankle-clonus on both sides; the radial, ulnar, and triceps reactions were absent. She had complete control over her bladder and rectum. 'There was no anæsthesia. The pupils wert normal. She complained greatly of pain in the various joints, but especially in the left elbow and ankle. The general health had remained good.

This case presents so many points of similarity to Case VII. that we are tempted to seek in the latter the explanation of the symptoms. There is the same sudden paralysis with anæsthesia, followed by spastic symptoms, the anxsthesia passing off gradually, the bladder and rectum, at first paralysed, recovering their functions. There is, however, this important difference, that, whereas in Case VII. we have evidence of destruction of a portion of the grey matter of the cord, causing utrophic paralysis and some permanent impairment of sensi- 
tion, thcre are here no symptoms but such as might arise from compression of the cord. Further, in the present instance, the symptoms are absolutely symmetrical. We are thus led to look for some cause of general compression of the cord, at a point near the origin of the 4th or 5th cervical nerve. In Case VII., the compressing agent was a central hæmorrhage, causing destruction in its immediate vicinity. In the present instance we can hardly assume this to have been the lesion, as, if we do so, we must suppose an effusion of blood large enough to cause continued pressure on the whole of the structures of the cord, and yet so small as not to have extended into the anterior cornua. If, however, the hæmorrhage were meningeal, lying entirely outside the cord, it might very well cause such pressure without producing any destruction of its substance. Now, a moment's consideration will show, that the accident was of just such a nature as to produce this lesion. An examination of the neck, or of such a plate as that given on p. 302, vol. i., of Quain's 'Anatomy' (8th edition), will show, that if a bullet were to enter "immediately below and behind the left mastoid process," and pursue a straight course to a point "some 3 inches to the right of the 5th cervical spinous process," it would cross the vertebral column about the level of the 4th cervical spine, that is, about the level of the 5th cervical nerve, the upper limit of the paralysis and anæsthesin in our case. Now, the bullet was flattened at the apex as if it had struck some bone, and as it entered below the mastoid process, the only bone in its track would be a portion of the spine. It would then appear that the bullet struck the spina] column somewhere immediately above the 5th cervical nerve, and it probably did not penetrate the cord, or there would not have been the subsequent partial recovery. It appears to us, then, more than probable that it injured in its passage the spinal meninges, giving rise to hæmorrhage sufficiently profuse to compress the cord. It may be said that the instantaneous appearance of the symptoms negatives this view of their production, but we must remember that the only authority for this sudden onset is the patient herself, who was doubtless not at the time in a judicial frame of mind, having been shot by her husband, and having then to witness the latter commit suicide. 
That she should fall is not surprising; she would then be confuserl, probably faint for some little time, and that time would be quite sufficient for the effusion of a quantity of blood from the rachidian veins. It is also possible that a small piece of bone may have been detached from one of the vertebræ and driven in upon the cord, so as to press upon without lacerating it which would naturally cause instant symptoms of compression, but which accords less sutisfactorily than does the theory of meningeal hæmorrhage with the partial recovery which ensued.

In concluding a review of the above cases, there are a few points to which reference may be made, and for the consideration of which it is more convenient to regard the cases collectively.

We are at once struck by the relatively large number of cases of hæmorrhage within the vertebral canal, constituting at least three, and probably four, out of a total of nine cases of injury to the cervical region of the spine. The number of these cases occurring in actual practice is probably much under-estimated, many of them being regarded as instances of concussion of the spine, without definite organic lesion. The symptoms are frequently complicated, and without a careful consideration of the origin and course of the affected tracts, would appear to be inexplicable on the hypothesis of a single lesion. If, however, these symptoms be fully investigated with the assistance of an accurate knowledge of the anatomy of the cord, they will probably in most cases be found to be clearly due to some gross local lesion. It is to be regretted that of the numerous reported cases of spinal injury, a minority only are sufficiently detailed to permit of an arcurnte dingnosis, it being only too customary to use such loose expressions as "partial paralysis of the upper limbs."

Another cause of the comparative neglect of bacmatomyelia as a result of injuries to the spine, is the relative infrequency of post-mortem examinations verifying this condition. These cases are not nearly so fatal as fractures and dislocations, and their true pathology is therefore not fully cleared up. Thus we find that of our five cases of fracture all were fatal, whereas of the four cases of hemorrhage only one died. Under thesc 
circumstances the only possible means of diagnosis is the demonstration that all the symptoms may be due to a single focus of injury ; but where such demonstration is practicable, we submit that a diagnosis of hæmorrhage should always be preferred to one which regards the case as an instance of that vague and somewhat theoretical affection, "concussion of the spinal cord."

We notice also the tendency of hæmorrhage into the cord to occur not very far from the level of the 4th or 5th cervical nerve, and we think that a simple mechanical consideration will explain this localisation. In Case IX. the direction taken by the bullet was, of course, a pure accident, and we may therefore omit that case from consideration. But in all the other three instances (Cases VI., VII., and VIII.) of hæmorrhage, we have seen reason to believe that the cord lesion was the result of an acute bend of the cervical portion of the spinal column. Now, a glance at a properly-articulated skeleton or well-drawn picture of the spine will show that the most anterior of the cervical vertebræ are the 4th and 5th, with their intervening disc. If, now, this region of the spine be overextended, either from a blow on the back of the neck, or from forcing back of the head or trunk, these two vertebræ will form the apex of the angle which is produced, and here, therefore, will be the most acute bend of the cord. Thus it happens that in all such injuries the cord is more stretched at this point than at any other, and is therefore more subject to a laceration of its blood-vessels, and the production of a hæmorrhage.

Finally we may note the relative frequency in our cases of certain well-recognised symptoms of injury to the spine.

As regards external deformity, we find this present only in one case (Case I.), there being in none of the others the slightest local indication of the severe injury which had been sustained.

Hyperæesthesia was observed in one case only (Case IX.), but in all the three cases which recovered (Cases VII., VIIl., and IX.), there was observed a sensation of tingling in the parts previously anæsthetic, as the anæesthesia was gradually passing away. 
Priapism was present in all the cases of fracture during the remainder of life. Of the three cases of hæmorrbage occurring in males, it was present in one alone (Case VI.), and even here it existed for about twenty-four hours only. It would thus appear that the fibres connecting the lumbar centre with the brain are situated at some considerable distance from the centre of the cord, so as either altogether to escape, or readily to recover from the pressure of a central hæmorrhage.

In the same way we find that the fibres connected with the bladder-centre are not liable to suffer from prolonged compression by a central hæmorrhage. Thus there was permanent retention of urine in all the cases of fracture. On the other hand, looking at the cases of hæmorrhage, we find retention lasting one day only in Case VI., and four days in Case VII.; while in Case VIII. there was no bladder trouble at all. In Case IX., a female, there was incontinence for some weeks, but not permanently. Can it be that the implicated fibres are situated near the periphery of the cord, that they thus escape compression or rapidly recover in the cases of central hæmorrhage; but that, owing to the hæmorrhage in Case IX. being meningeal, they are more directly exposed to a pressure, and therefore incapacitated for a longer period?

The present cases throw no light on the chemical changes which the urine may undergo. Two of them were examined at an early period for sugar and albumin, with negative results. In Case $I$. decomposition and alkalinity set in alout the end of the first veek, but the other cases give no indication of the period at which this change usually occurs, all having either died or regained control orer the bladder before the fourth day, with the exception of one which was only seen long after the injury.

$B e d$-sores were noted in Case I. at the time of admission, four dirys after the accident; all the other cases of fracture died within a few hours, before their development was possible, and they did not appear in any of the cases of hæmorrhage.

The condition of the pulse was noted in Cases I., III., V., and VII. In the first three of these it had the characters usually described in lesions of the cervical cord, being slow, full and of low tension. In Case VII. it was quick, but the 
observations were only made after the setting in of the febrile reaction due probably to myelitis. In Case IX. it was quite normal at the time the patient came under observation, five weeks after the accident. Case III. is, however, evidence that the pulse-rate may increase with rise of temperature, a pulse of 130 being rapid even with a temperature of $103^{\circ}$.

As is usually the case in spinal injuries, the temperatures observed were sufficiently remarkable, appearing to bear no relation to the nature and site of the injury; it is unnecessary to repeat the figures given above, no classification of cases being as yet possible.

The condition of the pupils and palpebral fissures is interesting, not only from a scientific point of view, but also because changes are very constant and are highly unlikely to be simulated in any case of attempted deception. Whether or not we accept the existence of a cilio-spinal centre in the cord, there can be no doubt that dilator fibres for the iris, and fibres supplying the muscle of Müller pass downwards to abont the level of the last cervical or first dorsal nerve-root, and thence outwards to join the sympathetic by means of the rami communicantes, and that these fibres are liable to be injured by any lesion of the cord above this level. The affection may, however, be overlooked if bilateral, being distinctly visible only in a dim light, because in bright light contraction is normally present and therefore would not be remarkable. In Case I. we find imperfect dilatation of the pupil on both sides, lasting until the closing stages, when there was dilatation, owing probably to the iris assuming the position of rest from paralysis of all its muscles, preceding death. In Case II. the pupils were said to be " normal," but this was probably owing to their not being properly examined in diffused light. In Cases III., V., and VI. there was no doubt about the contraction both of the pupils and of the palpebral fissures. In Case IV. the pupils were dilated, but death occurred before the subsidence of the first shock of the accident. In Case VI. the contraction was much more marked on the right side, coincidently with the greater extension of the hæmorrhagic focus on that side. In Case VII., where the lesion was more extensive on the left side, the left pupil only was contracted. 
In Cases VIII. and IX., where the injuries were less severe the pupils had altogether escaped. In Case III. the paralysis of Müller's muscle gave rise to a very remarkable sensation of softness and compressibility of the eyeball.

The last symptom to which I wish to refer is the condition of the cutaneous reflexes and tendon reactions below the sent of the lesion. On this subject we have notes in six of the cases only. We see at once that there is an important distinction to be drawn between the condition of the reflexes in the earlier and in the later periods after the injury. As regards cutaneous reflexes, they were noted as absent immediately or very shortly after the accident in Cases I., V., and VI., and they were lost later on in Cases VII. and IX.; beyond this there was no examination, but the results are exactly in accordance with the common observation that cutaneous reflexes are usually diminished or lost in cases where communication is cut off between the cerebral cortex and the periphery. The reason of this change is perhaps not yet satisfactorily explained, but as it is generally recognized as a matter of daily observation in all diseases of the nervous system, we need not dwell upon it longer at present.

As regards the tendon reactions, we find a most interesting condition. In Cases I., V., and VI. they were absent immediately after the occurrence of the injury, their early condition not being noted in any of the other cases. On $\dot{a}$ priori grounds we would expect that a complete transverse lesion of the cord, high up, would, by removing the influence of cerebral inhibition, tend to increase the activity of the tendon reactionsthe knee-jerk, and ankle-clonus. Such is the change soon after a transverse myelitis, after compression of the cord, and after degeneration of the lateral columns. Here, however, the exactly opposite condition is produced. Probably the true explanation of this peculiarity is, that the shock of the accident acts as a powerful depressant of reflex action, and is thus more than able to counterbalance the increased activity which the reflex centres should normally acquire on being relieved from the repressing influence of cerebral inhibition. The facts would thus appear to be of the same order as the well-known observations of Goltz, that upon section of the 
spinal cord of the dog in the neck the lumbar reflex centres for the bladder, rectum, and generative organs are temporarily paralysed. This condition of paralysis of reflex action from shock is constantly seen clinically in cases of retention of urine following upon operations or injuries of quite distant parts-as, for instance, in a case which I have seen quite recently, where retention of urine lasted for two days after the performance of Mac Ewen's operation for genu valgum. If such be the true explanation of this loss of the deep reflexes, we should expect them soon to be restored to their normal condition, but from the very nature of the cases this is a change which can seldom be observed. Thus Cases V. and VI. died within a few hours of the accident, there being no opportunity for the reflex centres of the cord to recover their functions. Case I., it is true, lingered longer, but he remained throughout in a condition of depressed vitality not favourable to energetic reflex action, and we know well that in many cases of general depression the reflexes are diminished or absent. Further, it is to be remembered that the determination of a slight knee-jerk is by no means easy in a patient necessarily recumbent on a water-bed. But, turning to some of the later cases, we find evidence that the knee-jerk does, as a rule, return before very long, the best example being Case IX., where at the fifth week after the accident the knee-jerk was apparently normal in degree. Finally, we find that in older cases, where there has been time for the development of a descending degeneration of the pyramidal tracts, there is, as is usual under such circumstances, a well-marked intensification of the tendon reactions, as evidenced by Cases VII., VIII., and IX. 